\title{
Systemic inflammation and comorbidity in COPD: a result of 'overspill' of inflammatory mediators from the lungs? Review of the evidence
}

\author{
Nicola J Sinden, Robert A Stockley
}

Lung Investigation Unit, Queen Elizabeth Hospital, Birmingham, UK

\section{Correspondence to} Robert A Stockley, Lung Investigation Unit, Queen Elizabeth Hospital, Edgbaston, Birmingham B15 2TH, UK: rob.stockley@uhb.nhs.uk

Received 29 October 2009 Accepted 21 February 2010 Published Online First 13 July 2010

\section{ABSTRACT}

Chronic obstructive pulmonary disease (COPD) is characterised by an inflammatory response by the lungs to inhaled substances such as cigarette smoking and air pollutants. In addition to the pulmonary features of COPD, several systemic effects have been recognised even after controlling for common aetiological factors such as smoking or steroid use. These include skeletal muscle dysfunction, cardiovascular disease, osteoporosis and diabetes. Individuals with COPD have significantly raised levels of several circulating inflammatory markers indicating the presence of systemic inflammation. This raises the issue of cause and effect. The role of tumour necrosis factor $\alpha$ in COPD is thought to be central to both lung and systemic inflammation and has been implicated in skeletal muscle dysfunction, osteoporosis and type 2 diabetes. It has been hypothesised that inflammation in the lung results in 'overspill' into the circulation causing systemic inflammation. There is supportive evidence that protein movement can occur from the lung surface to the systemic circulation. Evidence from inhaled substances such as air pollutants and cigarette smoke has demonstrated a temporal link between the inflammatory process in the lung and systemic inflammation. Also, studies have shown alterations in circulating inflammatory cells in patients with COPD compared with controls which may reflect the effects of inflammatory mediators (derived from the lung) on circulating cells or the bone marrow. This paper considers the concept of 'overspill' in depth, reviews the current evidence and highlights problems in generating direct evidence to support or refute this concept.

\section{INTRODUCTION}

Chronic obstructive pulmonary disease (COPD) is characterised by an intense inflammatory process in the airways, parenchyma and pulmonary vasculature. The lung inflammatory response is characterised by increased numbers of neutrophils, ${ }^{1}$ macrophages and $\mathrm{T}$ lymphocytes ${ }^{2}$; augmented concentrations of proinflammatory cytokines such as leukotriene (LT)B4, ${ }^{3}$ interleukins (IL)-1, 6 and $8^{4}$ and tumour necrosis factor $\alpha(\mathrm{TNF} \alpha)^{5}$; and evidence of oxidative stress. It has been recognised that systemic features and other diseases are more common in COPD, ${ }^{6}$ including skeletal muscle dysfunction, ${ }^{7}$ cardiovascular disease, ${ }^{8}$ osteoporosis ${ }^{9}$ and diabetes, ${ }^{10}$ all of which are thought to have a similar inflammation-based pathophysiology to COPD. Indeed, COPD is associated with evidence of systemic oxidative stress, ${ }^{11}$ activation of circulating inflammatory cells ${ }^{12}$ and increased plasma levels of proinflammatory cytokines. ${ }^{13}$ A systematic review supported this and concluded that individuals with COPD had significantly raised levels of several markers of inflammation including C-reactive protein (CRP), IL-6, fibrinogen, activated leucocytes and TNF $\alpha$, confirming the presence of systemic inflammation. ${ }^{14}$ However, whether this represented independent physiological processes, common generalised processes or 'overspill' inflammation from one organ to another remains uncertain. This review examines the evidence and specifically addresses the feasibility of 'overspill' and its complexity.

\section{Role of systemic inflammation in systemic features of COPD}

The role of TNF $\alpha$ in COPD is thought to be central to both lung and systemic inflammation. ${ }^{15} 16$ Plasma TNF $\alpha$ and its soluble receptor are increased in patients with COPD. ${ }^{17} 18$ Di Francia et al ${ }^{16}$ showed that, when serum TNF $\alpha$ was measured by immunoradiometric assay, there were significantly higher $(p<0.001)$ levels in patients with COPD with weight loss than in healthy controls. Similarly, Karadag et $a l^{19}$ reported higher serum TNF $\alpha$ levels in both stable COPD patients and those with an exacerbation compared with controls, and serum TNF $\alpha$ levels correlated with disease severity. ${ }^{20}$ Furthermore, circulating monocytes and bronchoalveolar lavage $\mathrm{T}$ lymphocytes harvested from patients with COPD produce more TNF $\alpha$ than those from healthy controls. ${ }^{21} 22$ The role of TNFa in muscle wasting is controversial, with some studies showing a relationship ${ }^{23}$ while others do not. ${ }^{24}{ }^{25}$ However, measurements of TNFa do not necessarily equate to function as rapid receptor binding will remove it from the biological fluid. TNF $\alpha$ may affect muscle cells in a number of ways. In differentiated myocytes studied in vitro, TNF $\alpha$ activates the transcription factor nuclear factor- $\kappa \mathrm{B}$ and degrades myosin heavy chains through the ubiquitin/proteasome complex. ${ }^{26}$ Studies have shown that dysregulation of the ubiquitin/proteasome system contributes to the loss of muscular mass caused by sepsis or tumours in rats, ${ }^{27}$ suggesting that this is a likely mechanism in COPD. In addition, TNF $\alpha$ can induce apoptosis in several cell systems including skeletal muscle in patients with COPD with weight loss. ${ }^{6}$ Alternatively, the effects of TNF $\alpha$ may be less direct inducing other proinflammatory cytokines that are likely to contribute to the persistence and amplification of the inflammatory cascade. ${ }^{26}$ Patients with COPD with increased resting energy expenditure 
and reduced fat-free mass also have increased levels of acute phase reactant proteins and other inflammatory cytokines in their serum such as CRP, lipopolysaccharide binding protein and IL- $8,{ }^{13}$ indicating a more general inflammatory response.

Bolton et al ${ }^{9}$ confirmed that osteopenia was a feature of COPD and also associated with an increase in circulating TNF $\alpha$. Low bone mineral density and high fracture rates have been demonstrated in patients with COPD not receiving systemic glucocorticoids ${ }^{28}$ and impaired forced expiratory volume in $1 \mathrm{~s}$ $\left(\mathrm{FEV}_{1}\right)$ has been shown to be an independent predictor of osteoporosis in studies of patients with and without COPD. ${ }^{29}$ Furthermore, TNF $\alpha$ and IL-1 have been implicated in the pathophysiology of osteoporosis, ${ }^{30}$ providing a putative direct link.

Despite this evidence and hypothesis, treatment with TNF $\alpha$ inhibitors has not shown significant short-term benefit in patients with $\mathrm{COPD},{ }^{31}$ although etanercept may reduce hospital admissions. ${ }^{32}$ This may suggest that TNF $\alpha$ has little role in COPD. However, COPD is a highly complex inflammatory disease in which many other cytokines and mediators are involved, and blocking a single cytokine does not necessarily lead to a clinically significant effect. ${ }^{33}$ Alternatively, the relatively low levels seen in COPD and the slow progression of the disease may mean that TNF $\alpha$ inhibition requires a long period before any effect (other than on an acute event) can be clearly identified or dismissed.

Persistent systemic inflammation has also been linked to atherosclerosis, ischaemic heart disease, stroke and cardiovascular mortality. Circulating CRP is an independent predictor of vascular death ${ }^{34}$ and rises during an acute exacerbation of COPD. Reduced $\mathrm{FEV}_{1}$ is a marker of cardiovascular mortality independent of age, gender and smoking history ${ }^{35}$ and is also related to plasma CRP levels, ${ }^{36}$ again suggesting a pathophysiological link. Patients with COPD have elevated plasma fibrinogen levels ${ }^{37}$ which are associated with an increased prothrombotic risk. Exacerbations are associated with a rise in serum IL-6 levels leading to a further rise in plasma fibrinogen and increasing CRP production. Thus, acute infection leads to changes that may have a role in predisposing to coronary heart disease or stroke and hence explain the increased mortality observed within a few months of hospital admission. ${ }^{38}$

These data indicate clearly that common cytokines or pathways are involved in the pathophysiology of COPD and its comorbidities, although the exact mechanisms are far from clear and direct evidence of 'overspill' is lacking.

\section{PROTEIN MOVEMENTS BETWEEN THE LUNG AND CIRCULATION}

\section{Evidence of protein movement from serum to lung secretions}

There is abundant evidence that protein movement can take place from the systemic circulation to lung secretions. Gorin et $a l^{39}$ measured the flux of albumin between the vascular space and the pulmonary interstitial and luminal lining fluids in 20 adult sheep with chronic lung lymph fistulas. They concluded that proteins present in alveolar lavage fluid and also present in plasma reach the alveolar space by a simple diffusion process which was relatively free into the interstitium although markedly restricted by the epithelial membrane. Radiolabelled albumin injected into the peripheral circulation subsequently appears in lung secretions. ${ }^{40}$ Also, a rise in the concentration of $\alpha_{1}$-antitrypsin in lung secretions occurs following intravenous administration of the protein to deficient subjects. ${ }^{41} 42$ The secretion to serum concentration ratio of proteins is dependent on the plasma concentration, is inversely proportional to protein size indicating a degree of filtration and is influenced by the presence of inflammation which increases epithelial leakability. ${ }^{43}$

\section{Evidence for movement from the lungs to the systemic circulation \\ Direct evidence}

There is evidence that proteins can move in the opposite direction from the lung surface to the systemic circulation. Smith et $a l^{44}$ administered aerosols of plasma-derived $\alpha_{1}$-antitrypsin to the lungs of dogs and sheep. The protein was subsequently found in the plasma of dogs, rose slowly to a maximum value at $48 \mathrm{~h}$, remained raised from $48-72 \mathrm{~h}$ and then disappeared slowly by $144 \mathrm{~h}$. The aerosolised $\alpha_{1}$-antitrypsin was also found in the lymph and plasma of sheep with a reverse gradient supporting retrograde movement. Vogelmeier et al ${ }^{45}$ showed that both recombinant secretory leucoprotease inhibitor and recombinant $\alpha_{1}$-antitrypsin appeared in lung lymph of sheep following aerosolisation. Finally, Hubbard et a ${ }^{46}$ administered aerosolised human plasma $\alpha_{1}$-antitrypsin to 12 patients with homozygous $Z$ type $\alpha_{1}$-antitrypsin deficiency and mild to moderate emphysema and to anaesthetised sheep with indwelling thoracic lymph duct catheters for direct assessment of lung permeability. Aerosolised $\alpha_{1}$-antitrypsin diffused across the respiratory epithelium and entered lung interstitial lymph (in sheep) and was detected in the systemic circulation (in both sheep and humans)

In addition, aerosolised insulin has a rapid systemic therapeutic effect. ${ }^{47}$ These data clearly confirm the ability of proteins in the airway to move into the systemic circulation, although this is also likely to be influenced (at least in part) by factors outlined above that determine protein movement in the opposite direction.

\section{Evidence that inhaled substances can influence systemic} inflammation

In chronic diseases the relationship between local and systemic inflammation is in a stable state. However, the temporal relationship between factors that change local and systemic inflammation provides clearer evidence of an 'overspill' phenomenon.

For instance, there is evidence that inhaled substances such as air pollutants can lead to a subsequent systemic inflammatory response. Alveolar macrophages (AM) are the most likely link between the inflammatory process in the lung and the systemic response because they are cells responsible for ingesting and clearing inhaled particles. ${ }^{48}$ Human and animal studies have shown that phagocytosis of these particles by AM leads to pulmonary inflammation with an increased number of activated $\mathrm{AM}^{49}$ The interaction of $\mathrm{AM}$ with atmospheric particles increases their phagocytic activity, oxidant production and the release of inflammatory mediators such as TNF $\alpha^{50}{ }^{51}$ This is accompanied by raised levels of circulating cytokines, systemic inflammation and microvascular endothelial dysfunction in the systemic circulation. ${ }^{52-55}$ It has been suggested that, following phagocytosis of particulate matter, cytokines released by activated AM act on the bone marrow to mobilise platelets and leucocytes. Indeed, studies have shown that particle exposure leads to an acute leucocytosis in humans ${ }^{56}$ and animals, ${ }^{57}$ supporting this concept. The instillation of mediators secreted by $\mathrm{AM}$ exposed to particulate matter with diameter $<10 \mu \mathrm{m}$ $\left(\mathrm{PM}_{10}\right)$ ex vivo into lungs produces a bone marrow response similar to that produced by instilling the particles themselves into the lungs. ${ }^{57} 58$ This suggests that AM are capable of initiating both a local and systemic inflammatory response when $\mathrm{PM}_{10}$ are deposited in the lung. In support of this, Van Eeden et $a l^{55}$ found that circulating levels of IL-1, IL- 6 and granulocyte macrophage colony stimulating factor (GM-CSF) were raised in subjects exposed to high levels of $\mathrm{PM}_{10}$ during an episode of 
acute air pollution. The results showed that a range of different particles stimulate AM to produce proinflammatory cytokines, and these cytokines are also increased in the blood of subjects during an episode of acute atmospheric air pollution indicating a temporal link between these cytokines and the systemic response.

Salvi et al ${ }^{59}$ exposed human healthy volunteers to air and diluted diesel exhaust for $1 \mathrm{~h}$. Blood sampling and bronchoscopy were performed $6 \mathrm{~h}$ after each exposure to obtain airway lavages and endobronchial biopsies. There was a significant increase in neutrophils and B lymphocytes in the bronchial lavage following exposure to diesel exhaust, together with increases in histamine and fibronectin. The bronchial biopsies obtained $6 \mathrm{~h}$ after exposure to diesel exhaust showed a significant increase in neutrophils, mast cells, CD4+ and CD8+ T lymphocytes together with upregulation of the endothelial adhesion molecules intercellular adhesion molecule- 1 and vascular cell adhesion molecule- 1 . At the same time, significant increases in neutrophils and platelets were observed in peripheral blood following exposure to diesel exhaust, suggesting stimulation of marrow release. These data provide clear evidence that inhaled pollutants can lead to a temporal association between the expected pulmonary response and an identified systemic inflammatory effect.

Cigarette smoking is the most important cause of COPD, although the fact that only a proportion of smokers develop clinically important airflow obstruction suggests a genetic predisposition. Rusznak et $a l^{60}$ examined cultured human bronchial epithelial cells exposed to cigarette smoke from neversmokers, and smokers with and without COPD. They concluded that bronchial epithelial cells from smokers with COPD were different, showing greater response to the effects of cigarette smoke by increasing transepithelial permeability and reducing the protective role of cellular glutathione (an important intracellular antioxidant). Also, there was increased release of key proinflammatory mediators (IL-1 $\beta$ and soluble intercellular adhesion molecule-1) from the COPD cells in response to the smoke challenge. There have been conflicting data on the response of AM to cigarette smoke. Some authors have reported reduced cytokine production following exposure to cigarette smoke. ${ }^{61}$ However, Terashima et al ${ }^{62}$ demonstrated that AM, when stimulated by cigarette smoke, produce factors such as TNF $\alpha$, IL-1, IL-6 and IL-8, as well as haematopoietic growth factors such as GM-CSF and G-CSF, which are capable of stimulating the proliferation and release of polymorphonuclear leucocytes and monocytes from the bone marrow and hence may account for the blood neutrophilia of smokers. ${ }^{63}$

Overall, these experimental data indicate that AM and bronchial epithelial cells are critically important in processing inhaled noxious gases and particles. Many of the mediators they produce and/or their effects are also identified systemically in COPD, suggesting that these mediators have been generated in and released from the lung into the circulation contributing to the systemic inflammatory response. Although other cells are able to produce these mediators, the importance of AM in producing systemic inflammation has been demonstrated best using animal models. AM-depleted rats show a substantially reduced systemic inflammatory response following acute alveolar hypoxia compared with controls, ${ }^{64}$ indicating a key role for this cell.

Experimental data also exist demonstrating a clear relationship between the systemic inflammation induced by instillation of air pollution particles in the lung and progression of atherosclerosis. Suwa et al $l^{65}$ showed that, when Watanabe Heritable Hyperlipidaemic rabbits (that develop atherosclerosis naturally) were exposed to ambient particles, they demonstrated a brisk systemic inflammatory response which was associated with progression of their atherosclerosis. Furthermore, the extent of the atherosclerotic burden was directly proportional to the number of AM that contained the particulate matter. These data again suggest a direct link between lung and systemic inflammation and subsequently inflammation-related comorbidity.

Alternatively, there is evidence that inhaled ultrafine particles are able to translocate from the lung into the systemic circulation in humans and animals and directly activate a systemic response. ${ }^{66}$ In animal studies, intratracheal instillation of diesel exhaust particles promoted femoral venous thrombosis in a dose-dependent manner. Furthermore, the direct addition of diesel exhaust particles to untreated blood also caused platelet aggregation. These prothrombotic effects persisted for up to $24 \mathrm{~h}$ after instillation and provide a plausible mechanistic explanation for the epidemiologically established link between air pollution and acute cardiovascular effects.

\section{Indirect evidence}

The lung inflammatory response is characterised by increased numbers of neutrophils, macrophages and $\mathrm{T}$ lymphocytes and augmented concentrations of proinflammatory cytokines, which are similar to changes found in the systemic circulation. Studies have shown alterations in circulating inflammatory cells in COPD which may reflect the effects of inflammatory mediators derived from the lung on circulating cells or the bone marrow. For instance, Burnett et al ${ }^{67}$ showed that neutrophils isolated from patients with COPD had enhanced chemotaxis in response to a chemotactic peptide (suggesting that they had been primed) and increased spontaneous extracellular proteolysis. Noguera et al ${ }^{68}$ found that patients with COPD showed abnormal expression of neutrophil and endothelial adhesion molecules, and reported downregulation of a G-protein subunit involved in the intracellular transduction pathway. The same authors ${ }^{12}$ found that the production of reactive oxygen species was higher in circulating neutrophils harvested from patients with COPD than from smokers with normal lung function or non-smokers. These studies of enhanced neutrophil function in COPD also support a systemic influence related in some way to the lung abnormality.

Blood lymphocytes isolated from patients with COPD have been less well studied, although abnormal function of circulating lymphocytes in COPD has been reported ${ }^{69}$ which relates significantly to disease severity.

Monocytes also accumulate in the lungs of smokers in response to cigarette smoke. ${ }^{70}$ It is likely that smoke-activated macrophages release monocytic chemokines (eg, monocyte chemoattractant protein-1) into the peripheral blood. ${ }^{71}$ Besides being chemoattractant, these chemokines can also contribute to the subsequent priming of - and increased expression of-CD43 and $\mathrm{CD} 11 \mathrm{~b}$ receptors on circulating monocytes. ${ }^{72}$ Activated monocytes have also been implicated in the development of atherosclerosis ${ }^{73}$ which is increased in patients with COPD.

Patients with COPD have higher circulating levels of IL- 6 than controls. $^{74}$ This cytokine is a potent stimulator of CRP production by the liver and may account for the increase in circulating CRP found in patients with COPD. ${ }^{75}$ In stable $\mathrm{COPD}$, plasma concentrations of $\mathrm{CRP}$ are related to mortality in patients with mild to moderate disease ${ }^{76}$ but not in those with severe and very severe disease. ${ }^{77}$ Raised CRP relates to health status, exercise capacity and body mass index (BMI) ${ }^{78}$ as well as cardiovascular disease, ${ }^{34}$ indicating a clear association with both lung-related and systemic features.

Surfactant protein D (SPD) is a large multimeric collagenous glycoprotein produced mainly by type 2 pneumocytes in the 
Figure 1 Diagrammatic representation of mechanisms that influence the process of 'overspill' and its detection. Several processes will influence the release of lung cytokines into the circulation. (1) Cytokines are released from bronchial epithelial cells into lung secretions. (2) Other inflammatory cells may also release the same cytokines into the lung secretions. (3) These cytokines may move into the interstitium by diffusion depending on size and inflammation. (4) Migrating monocytes, tissue macrophages or other inflammatory cells may release cytokines directly into the interstitial space. These proteins may not necessarily be present in airway secretions. (5) Protein movement may be facilitated across the epithelial cells or secreted basolaterally. The proteins in the interstitium can then enter the lymph and hence systemic circulation. (6) Local release of a cytokine may lead to downstream production of a second cytokine locally or in the interstitium with subsequent passage into the circulation.

lungs, although endothelial cells and glandular cells in the gastrointestinal tract can also produce small amounts. ${ }^{79}$ In a pilot study, ${ }^{80}$ serum SPD concentrations were found to be increased in patients with COPD and related to disease severity and symptoms. Since the lung is the major source of SPD production, this observation suggests that, with lung injury, SPD and (by implication) other locally produced proteins may leak from the lung compartments into the systemic circulation.

\section{Clinical evidence}

Sapey et $\mathrm{al}^{81}$ found that sputum levels of IL-1 $\beta$, TNF $\alpha$ and LTB4 correlated negatively with BMI, supporting the hypothesis that an increase in lung inflammation is associated with a lower body weight and previous studies have linked low BMI with systemic inflammation. ${ }^{23}$ This is an important observation, especially as TNF $\alpha$ has been implicated in the muscle loss of COPD. ${ }^{13} 1621$ However, the lung TNF $\alpha$ concentration did not correlate with the plasma level. The absence of a clear relationship between lung and systemic TNF $\alpha$ would be taken as lack of direct evidence of 'overspill', thereby questioning this as a mechanism.

\section{DIFFICULTIES IN PROVING THE CONCEPT OF 'OVERSPILL'}

Clearly, protein movement can occur from the airway into the circulation and circumstantial evidence exists indicating that airways disease and inflammation are associated with inflammatory changes in the circulation and an increase in inflammation-related comorbidity. It is therefore understandable that the concept of inflammatory cytokine 'overspill' should be implicated. However, a lack of correlation between airway cytokine concentrations and those in the circulation has failed to support this concept, ${ }^{82} 83$ although studies to date have involved small numbers of patients and may therefore have lacked sufficient power to support the 'overspill' theory.
Figure 2 Diagrammatic representation of mechanisms that influence the process of 'overspill' and its detection. Once in the circulation, other mechanisms will influence the measurement and downstream effects of proteins. (1) Receptor binding influences measurement of free cytokines. (2) Systemic release of one cytokine may lead to a downstream effect and the release of a second protein. It may be the second protein that is the systemic signal (eg, interleukin 6 leading to $\mathrm{C}$-reactive protein production). (3) Gene polymorphisms exist which may affect the response of the downstream marker to any given cytokine leading to differential production.

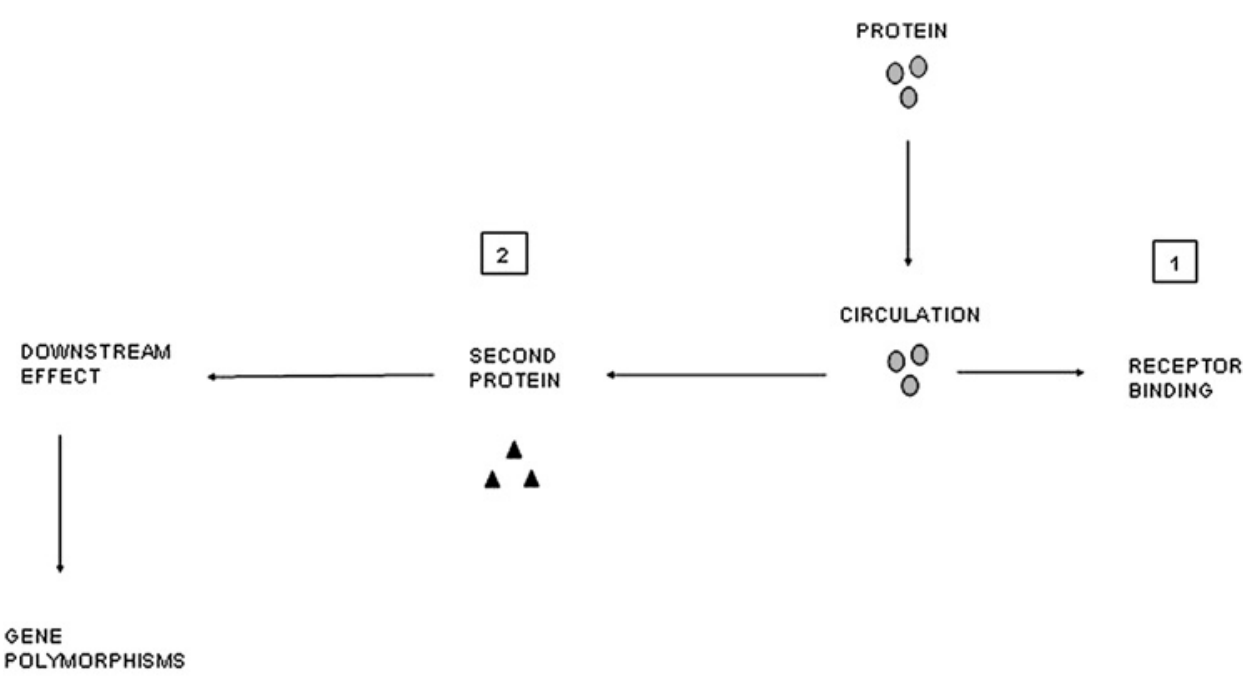


Nevertheless, this lack of correlation does not mean that 'overspill' has not occurred as many factors will influence the results. First, a protein in the airway has to pass into the interstitium, and hence lymph, in order to reach the circulation. This process will be dependent upon the 'leakability' of the epithelium and protein size (as shown for the reverse process from plasma to the airway). Second, facilitated transport may occur by processes including epithelial basolateral secretion of the same protein ${ }^{84}$ or migration of activated macrophages from the airway into the interstitium or vice versa, thereby secreting the same cytokines differentially in both compartments. There is also evidence that fluid balance in the lungs is regulated by active ion transport which is the likely mechanism for removal of alveolar oedema. ${ }^{85}$ The majority of patients with acute lung injury have impaired alveolar epithelial fluid transport, which is associated with a higher mortality. Under pathological conditions, these mechanisms may also influence movement of inflammatory mediators from the lungs to the systemic circulation, although further studies will be necessary to explore this. Third, protein concentration is difficult to quantify in airway secretions. This fluid is mobile in the airway moving upwards, is variably hydrated and usually contaminated during the collection process (lavage or expectoration). This results in highly variable dilution and the repeated measurements of inflammatory indices in the airways have marked intra- and inter-patient variability. ${ }^{81}$ Furthermore, proteins produced in the interstitial space may not be measured in airway secretions. Thus, even if the plasma level is constant, correlations will be difficult to identify with these factors influencing the potential source. Sequential sampling and averaging the data for an individual dramatically reduces this variability. ${ }^{81}$ Nevertheless, even with this methodology, direct measurements of TNF $\alpha$ and IL-1 in the secretions and plasma show no direct correlation. ${ }^{83}$

However, there are other complexities that will influence the result. Local release of cytokine A may lead to a local autocrine or paracrine effect, releasing cytokine $\mathrm{B}$ either into the same compartment or a different one in the lung, and it may be cytokine $\mathrm{B}$ that has the systemic effect. The volume of distribution of the cytokine is markedly different and receptor binding will influence measurement of free cytokine. In the lung, receptors are often saturated in the presence of marked inflammation leaving a surplus of free (and hence measurable) cytokine. This is unlikely in plasma where there are abundant circulating and tissue receptors resulting in rapid uptake of any leaked cytokine. This process may then result in a downstream 'overspill' effect with receptor binding of cytokine A stimulating systemic production of factor B (eg, IL-6 release leading to CRP production). ${ }^{86}$ Even this process itself does not represent a straight line effect. Polymorphisms of the CRP gene will result in differential responses to IL- $6^{85}$ and this may be important in cardiovascular mortality. ${ }^{87}$ These concepts are summarised in figures 1 and 2 .

These complexities make it generally unlikely that direct evidence (correlation between lung and plasma cytokine concentrations) for 'overspill' will be detected. At best we are left with inflammation relationships, and further extensive studies will be needed to confirm or indeed refute the concept of 'overspill.'

\section{CONCLUSION}

There is direct evidence from $\alpha_{1}$-antitrypsin and secretory leukoprotease inhibitor that protein movement occurs from the lungs to lymph and blood. SPD (which is predominantly produced in the lung) is elevated in the serum of patients with COPD and its concentration relates to disease severity and symptoms, providing further evidence for leaking of proteins from the lung to the systemic circulation. Evidence from inhaled substances such as air pollutants and cigarette smoke has demonstrated a temporal link between the inflammatory process in the lung and systemic inflammation. Experimental data indicate that AM and bronchial epithelial cells are critically important in processing inhaled noxious gases and particles, and that the mediators they produce are also identified in the systemic response in COPD. Studies have also consistently shown alterations in circulating inflammatory cells in COPD such as neutrophils and lymphocytes, indicating a downstream effect. Clinical effects of lung inflammation are clearly implied by correlations between secretion cytokine concentrations and BMI and the mechanisms of several comorbidities.

Proteins originating from the lung may have both direct and indirect effects systemically. A lack of correlation between lung and systemic concentrations of any single mediator does not mean that 'overspill' has not occurred. Proving the concept of 'overspill' has been difficult due to underpowered studies, methods of quantifying protein levels and a lack of awareness of the complex processes that affect the measurement or response. Clearly, further studies in this area are needed to confirm or refute the 'overspill' hypothesis.

\section{Competing interests None.}

Provenance and peer review Not commissioned; externally peer reviewed.

\section{REFERENCES}

1. Keatings VM, Barnes PJ. Granulocyte activation markers in induced sputum: comparison between chronic obstructive pulmonary disease, asthma, and normal subjects. Am J Respir Crit Care Med 1997;155:449-53.

2. Saetta M, Di Stefano A, Maestrelli P, et al. Activated T-lymphocytes and macrophages in bronchial mucosa of subjects with chronic bronchitis. Am Rev Respir Dis 1993;147:301-6

3. Profita M, Giorgi RD, Sala A, et al. Muscarinic receptors, leukotriene B4 production and neutrophilic inflammation in COPD patients. Allergy 2005;60:1361-9.

4. Chung KF. Inflammatory mediators in chronic obstructive pulmonary disease. Curr Drug Targets Inflamm Allergy 2005;4:619-25.

5. Keatings VM, Collins PD, Scott DM, et al. Differences in interleukin-8 and tumour necrosis factor-alpha in induced sputum from patients with chronic obstructive pulmonary disease or asthma. Am J Respir Crit Care Med 1996;153:530-4.

6. Agusti AGN, Noguera A, Sauleda J, et al. Systemic effects of chronic obstructive pulmonary disease. Eur Respir J 2003;21:347-60.

7. ATS/ERS. Skeletal muscle dysfunction in chronic obstructive pulmonary disease. A statement of the American Thoracic Society and European Respiratory Society. Am J Respir Crit Care Med 1999:159:S1-40.

8. Sin DD, Man SF. Chronic obstructive pulmonary disease as a risk factor for cardiovascular morbidity and mortality. Proc Am Thorac Soc 2005;2:8-11.

9. Bolton CE, lonescu AA, Shiels KM, et al. Associated loss of fat free mass and bone mineral density in chronic obstructive pulmonary disease. Am J Respir Crit Care Med 2004:170:1286-93

10. Schmidt MI, Duncan BB, Sharrett AR, et al. Markers of inflammation and prediction of diabetes mellitus in adults (Atherosclerosis Risk in Communities study): a cohort study. Lancet 1999:353:1649-52.

11. Rahman I, Morrison D, Donaldson K, et al. Systemic oxidative stress in asthma, COPD, and smokers. Am J Respir Crit Care Med 1996;154:1055-60.

12. Noguera A, Batle S, Miralles C, et al. Enhanced neutrophil response in chronic obstructive pulmonary disease. Thorax 2001;56:432-7.

13. Schols AM, Buurman WA, Staal van den Brekel AJ, et al. Evidence for a relation between metabolic derangements and increased levels of inflammatory mediators in a subgroup of patients with chronic obstructive pulmonary disease. Thorax 1996:51:819-24

14. Gan W0, Man SFP, Senthilselvan A, et al. Association between chronic obstructive pulmonary disease and systemic inflammation: a systematic review and a metaanalysis. Thorax 2004:59:574-80.

15. Churg A, Wang RD, Tai $H$, et al. Tumour necrosis factor-alpha drives $70 \%$ of cigarette smoke-induced emphysema in the mouse. Am J Respir Crit Care Med 2004;170:492-8

16. Di Francia M, Barbier D, Mege JL, et al. Tumour necrosis factor-alpha levels and weight loss in chronic obstructive pulmonary disease. Am J Respir Crit Care Med 1994;150:1453-5.

17. Takabatake $\mathbf{N}$, Nakamura $\mathrm{H}$, Abe $\mathrm{S}$, et al. The relationship between chronic hypoxemia and activation of the tumour necrosis factor alpha system in patients with chronic obstructive pulmonary disease. Am J Respir Crit Care Med 2000;161:1179-84 
18. Broekhuizen R, Grimble RF, Howell WM, et al. Pulmonary cachexia, systemic inflammatory profile, and the interleukin $1 \mathrm{~b}-511$ single nucleotide polymorphism. Am $J$ Clin Nutr 2005;82:1059-64.

19. Karadag F, Karul $A B$, Cildag 0 , et al. Biomarkers of systemic inflammation in stable and exacerbation phases of COPD. Lung 2008;186:403-9.

20. von Haehling $\mathbf{S}$, Hopkinson NS, Polkey Ml, et al. Elevated TNF alpha production in whole blood in patients with severe COPD: the potential link to disease severity. Wien Klin Wochenschr 2009;121:303-8.

21. De Godoy I, Donahoe M, Calhoun WJ, et al. Elevated TNF- $\alpha$ production by peripheral blood monocytes of weight-losing COPD patients. Am J Respir Crit Care Med 1996;153:633-7.

22. Barczyk A, Pierzchała W, Kon OM, et al. Cytokine production by bronchoalveolar lavage T lymphocytes in chronic obstructive pulmonary disease. J Allergy Clin Immunol 2006;117:1484-92.

23. Eid AA, lonescu AA, Nixon LS, et al. Inflammatory response and body composition in chronic obstructive pulmonary disease. Am J Respir Crit Care Med 2001:164:1414-18.

24. Karadag $\mathbf{F}$, Karul $A B$, Cildag 0 , et al. Determinants of $B M l$ in patients with COPD. Respirology 2004;9:70-5

25. Liu SF, Chin $\mathrm{CH}$, Wang CC, et al. Correlation between serum biomarkers and BODE index in patients with stable COPD. Respirology 2009;14:999-1004.

26. Li YP, Schwartz RJ, Waddell ID, et al. Skeletal muscle myocytes undergo protein loss and reactive oxygen-mediated NF-kB activation in response to tumour necrosis factor $\alpha$. FASEB J 1998;12:871-80.

27. Mitch WE, Goldberg AL. Mechanisms of muscle wasting. The role of the ubiquitinproteasome pathway. N Engl J Med 1996;335:1897-905.

28. Katsura H, Kida K. A comparison of bone mineral density in elderly female patients with COPD and bronchial asthma. Chest 2002;122:1949-55.

29. Lekamwasam S, Trivedi DP, Khaw KT. An association between respiratory function and hip bone mineral density in older men: a cross sectional study. Osteoporos Int 2005;16:204-7.

30. Cenci S, Weitzmann MN, Roggia C, et al. Estrogen deficiency induces bone loss by enhancing T-cell production of TNF- $\alpha$. J Clin Invest 2000;106:1229-37.

31. Matera MG, Calzetta L, Cazzola M. TNF-alpha inhibitors in asthma and COPD: we must not throw the baby out with the bath water. Pulm Pharmacol Ther 2010;23:121-8.

32. Suissa $\mathbf{S}$, Ernst $P$, Hudson M. TNF-alpha antagonists and the prevention of hospitalisation for chronic obstructive pulmonary disease. Pulm Pharmacol Ther 2008;21:234-8

33. Barnes PJ. Unexpected failure of anti-tumour necrosis factor therapy in chronic obstructive pulmonary disease. Am J Respir Crit Care Med 2007;175:866-7.

34. Ridker PM, Rifai N, Rose L, et al. Comparison of C-reactive protein and low-density lipoprotein cholesterol levels in the prediction of first cardiovascular events. $N$ Engl J Med 2002;347:1557-65

35. Sin DD, Wu L, Man SF. The relationship between reduced lung function and cardiovascular mortality; a population based study and systematic review of the literature. Chest 2005;127:1952-9.

36. Kony S, Zureik M, Driss F, et al. Association of bronchial hyperrresponsiveness and lung function with $\mathrm{C}$-reactive protein (CRP): a population based study. Thorax 2004;59:892-6

37. Wedzicha JA, Seemungal TA, MacCallum PK, et al. Acute exacerbations of chronic obstructive pulmonary disease are accompanied by elevations of plasma fibrinogen and serum IL-6 levels. Thromb Haemost 2000;84:210-15.

38. Almagro $\mathbf{P}$, Calbo $E$, Ochoa de Echaguen $A$, et al. Mortality after hospitalization for COPD. Chest 2002;121:1441-8.

39. Gorin AB, Stuart PA. Differential permeability of endothelial and epithelial barriers to albumin flux. J Appl Physiol 1979:47:1315-24.

40. Stockley RA. Measurement of soluble proteins in lung secretions. Thorax 1984;39:241-7.

41. Makino S, Reed CE. Distribution and elimination of exogenous alpha 1 antitrypsin. $J$ Lab Clin Med 1970;75:742-6.

42. Gadek JE, Klein HG, Holland PV et al. Replacement therapy of alpha 1 antitrypsin deficiency. Reversal of the protease-antiprotease imbalance within the alveolar structures of PiZ subjects. J Clin Invest 1981;68:1158-65.

43. Stockley RA, Mistry M, Bradwell AR, et al. A study of plasma proteins in the sol phase of sputum from patients with chronic bronchitis. Thorax 1979;34:777-82.

44. Smith RM, Traber LD, Traber DL, et al. Pulmonary deposition and clearance of aerosolized alpha-1-proteinase inhibitor administered to dogs and to sheep. J Clin Invest 1989;84:1145-54

45. Vogelmeier C, Buhl R, Hoyt RF, et al. Aerosolization of recombinant SLPI to augment antineutrophil elastase protection of pulmonary epithelium. J Appl Physiol 1990;69:1843-8

46. Hubbard RC, Brantly ML, Sellars SC, et al. Anti-neutrophil elastase defences of the lower respiratory tract in alpha 1 antitrypsin deficiency, direct augmentation with aerosol alpha 1 antitrypsin. Ann Intern Med 1989;111:206-12.

47. Steiner S, Pfützner A, Wilson BR, et al. Technosphere/insulin: proof of concept study with a new insulin formulation for pulmonary delivery. Exp Clin Endocrinol Diabetes 2002:110:17-21.

48. Lohmann-Matthes ML, Steinmuller C, Franke-Ullmann G. Pulmonary macrophages. Eur Respir J 1994;7:1678-89.

49. Tamagawa E, Bai N, Morimoto K, et al. Particulate matter exposure induces persistent lung inflammation and endothelial dysfunction. Am J Physiol Lung Cell Mol Physiol 2008;295:L79-85.
50. Goldsmith CA, Imrich A, Danaee $\mathrm{H}$, et al. Analysis of air pollution particulatemediated oxidant stress in alveolar macrophages. J Toxicol Environ Health 1998; 54:529-45.

51. Becker S, Soukup JM, Gilmour Ml, et al. Stimulation of human and rat alveolar macrophages by urban air particulates: effects on oxidant radical generation and cytokine production. Toxicol Appl Pharmacol 1996:141:637-48.

52. Ishii H, Hayashi S, Hogg JC, et al. Alveolar macrophage-epithelial cell interaction following exposure to atmospheric particles induces the release of mediators involved in monocyte mobilization and recruitment. Respir Res 2005:6:87.

53. Nurkiewicz TR, Porter DW, Barger M, et al. Systemic microvascular dysfunction and inflammation after pulmonary particulate matter exposure. Environ Health Perspect 2006:114:412-19.

54. Nemmar A, Nemery B, Hoet PH, et al. Silica particles enhance peripheral thrombosis: key role of lung macrophage-neutrophil cross-talk. Am J Respir Crit Care Med 2005;171:872-9.

55. Van Eeden SF, Tan WC, Suwa T, et al. Cytokines involved in the systemic inflammatory response induced by exposure to particulate matter air pollutants $\left(\mathrm{PM}_{10}\right)$. Am J Respir Crit Care Med 2001;164:826-30.

56. Tan WC, Qui D, Liam BL, et al. The human bone marrow response to acute air pollution caused by forest fires. Am J Respir Crit Care Med 2000:161:1213-17.

57. Terashima T, Wiggs B, English D, et al. Phagocytosis of small carbon particles by alveolar macrophages stimulates the release of PMN from the bone marrow. Am J Respir Crit Care Med 1997:155:1441-7.

58. Mukae H, English D, Anderson G, et al. Phagocytosis of $\mathbf{P M}_{10}$ by human alveolar macrophages stimulates the release of PMN from the bone marrow. Am J Respir Crit Care Med 1999;159:A317.

59. Salvi S, Blomberg A, Rudell B, et al. Acute inflammatory responses in the airways and peripheral blood after short-term exposure to diesel exhaust in healthy human volunteers. Am J Respir Crit Care Med 1999;159:702-9.

60. Rusznak C, Mills P, Devalia RJ, et al. Effect of cigarette smoke on the permeability and IL-1 $\beta$ and sICAM-1 release from cultured human bronchial epithelial cells of never-smokers, smokers, and patients with chronic obstructive pulmonary disease. Am J Respir Cell Mol Biol 2000:23:530-6.

61. Gaschler GJ, Zavitz CC, Bauer CM, et al. Cigarette smoke exposure attenuates cytokine production by mouse alveolar macrophages. Am J Respir Cell Mol Biol 2008;38:218-26

62. Terashima T, Klut ME, English D, et al. Chronic cigarette smoking causes sequestration of polymorphonuclear leukocytes released from the bone marrow in pulmonary capillaries. Am J Respir Cell Mol Biol 1998:20:171-7.

63. Schwartz J, Weiss ST. Cigarette smoking and peripheral blood leukocyte differentials. Ann Epidemiol 1994;4:236-42.

64. Gonzalez NC, Allen J, Blanco VG, et al. Alveolar macrophages are necessary for the systemic inflammation of acute alveolar hypoxia. J Appl Physiol 2007;103:1386-94

65. Suwa T, Hogg JC, Quinlan KB, et al. Particulate air pollution induces progression of atherosclerosis. J Am Coll Cardiol 2002;39:935-42.

66. Nemmar A, Hoylaerts MF, Hoet PH, et al. Possible mechanisms of the cardiovascular effects of inhaled particles: systemic translocation and prothrombotic effects. Toxicol Lett 2004;149:243-53.

67. Burnett D, Chamba A, Hill SL, et al. Neutrophils from subjects with chronic obstructive lung disease show enhanced chemotaxis and extracellular proteolysis. Lancet 1987;330:1043-6.

68. Noguera A, Busquets X, Sauleda J, et al. Expression of adhesion molecules and $\mathrm{G}$ proteins in circulating neutrophils in chronic obstructive pulmonary disease. $A m \mathrm{~J}$ Respir Crit Care Med 1998;158:1664-8.

69. Sauleda J, Garcia-Palmer FJ, Gonzalez G, et al. The activity of cytochrome oxidase is increased in circulating lymphocytes of patients with chronic obstructive pulmonary disease, asthma, and chronic arthritis. Am J Respir Crit Care Med 2000;161:32-5.

70. Shapiro SD. The macrophage in chronic obstructive pulmonary disease. Am J Respir Crit Care Med 1999;160:S29-32.

71. Masubuchi T, Koyama S, Sato E, et al. Smoke extract stimulates lung epithelial cells to release neutrophil and monocyte chemotactic activity. Am J Pathol 1998;153:1903-12.

72. Bergmann S, Siekmeier R, Mix C, et al. Even moderate cigarette smoking influences the pattern of circulating monocytes and the concentration of sICAM-1. Respir Physiol 1998;114:269-75.

73. Ross R. Atherosclerosis: an inflammatory disease. N Engl J Med 1999:340:115-26

74. Yasuda N, Gotoh K, Minatoguchi S, et al. An increase of soluble Fas, an inhibitor of apoptosis, associated with progression of COPD. Respir Med 1998:92:993-9.

75. Barnes PJ, Celli BR. Systemic manifestations and co-morbidities of COPD. Eur Respir J 2009;33:1165-85.

76. Dahl M, Vestbo J, Lange $\mathrm{P}$, et al. C-reactive protein as a predictor of prognosis in chronic obstructive pulmonary disease. Am J Respir Crit Care Med 2007;175:250-5.

77. de Torres JP, Pinto-Plata V, Casanova C, et al. C-reactive protein levels and survival in patients with moderate to very severe COPD. Chest 2008;133:1336-43.

78. Broekhuizen $\mathbf{R}$, Wouters EF, Creutzberg EC, et al. Raised CRP levels mark metabolic and functional impairment in advanced COPD. Thorax 2006;61:17-22.

79. Mason RJ, Greene K, Voelker DR. Surfactant protein A and surfactant protein D in health and disease. Am J Physiol 1998;275:L1-13

80. Sin DD, Leung R, Gan WO, et al. Circulating surfactant protein D as a potential lungspecific biomarker of health outcomes in COPD: a pilot study. BMC Pulm Med 2007;7:13 
81. Sapey E, Bayley D, Ahmed A, et al. Inter-relationships between inflammatory markers in patients with stable COPD with bronchitis: intrapatient and inter-patient variability. Thorax 2008;63:493-9.

82. Vernooy JH, Kucukaycan M, Jacobs JA, et al. Local and systemic inflammation in patients with chronic obstructive pulmonary disease: soluble tumour necrosis factor receptors are increased in sputum. Am J Respir Crit Care Med 2002;166:1218-24.

83. Sapey E, Ahmed A, Bayley D, et al. Imbalances between interleukin-1 and tumour necrosis factor agonists and antagonists in stable COPD. J Clin Immunol 2009:29:508-16.
84. Dupuit F, Jacquot J, Spilmont C, et al. Vectorial delivery of newly-synthesized secretory proteins by human tracheal gland cells in culture. Epithelial Cell Biol 1993:2:91-9.

85. Matthay MA, Robriquet L, Fang X. Alveolar epithelium: role in lung fluid balance and acute lung injury. Proc Am Thorac Soc 2005;2:206-13.

86. Eklund CM. Pro-inflammatory cytokines in CRP baseline regulation. Adv Clin Chem 2009:48:111-36.

87. Hage FG, Szalai AJ. The role of C-reactive protein polymorphisms in inflammation and cardiovascular risk. Curr Atheroscler Rep 2009;11:124-30.

\section{Lung alert}

\section{HIV and TB: excluding those without active disease and timing of concurrent therapy}

The WHO recommends the use of isoniazid preventive treatment for patients with HIV who do not have active tuberculosis (TB). Screening of patients with HIV for TB remains essential in order to enable early diagnosis and safe initiation of treatment. As the authors state, no guidelines exist as to when and how screening should occur for those patients with HIV to exclude active TB. Patients with HIV infection were enrolled in this trial from clinics in Cambodia, Thailand and Vietnam. Symptoms of patients who were culture positive for mycobacteria in sputum, urine, stool, blood or lymph nodes were compared with those who were culture negative.

The algorithm identified to have the most effective approach to ruling out a diagnosis of $\mathrm{TB}$ was asking questions related to a combination of three symptoms; cough of any duration, fever of any duration and night sweats lasting $\geq 3$ weeks, in the last 4 weeks. Within the population studied, with a TB prevalence of $15 \%$, the negative predictive value was $97 \%$, thus reducing the numbers of false-negative results. Therefore, in a limited-resource environment, the use of an algorithm without chest radiography may have the potential to exclude the presence of active $\mathrm{TB}$.

The optimal timing of antiretroviral therapy for those patients requiring concurrent treatment for TB has been a source of debate given the often poor outcomes associated with dual infection. The SAPIT (Starting Antiretroviral therapy at Three Points in Tuberculosis) trial identified 642 patients with HIV (CD4 count $<500$ ) and concurrent TB (positive sputum smear for acid-fast bacilli) in Durban, South Africa. Patients were assigned to receive 'integrated' antiretroviral therapy during TB treatment or 'sequential therapy' after the completion of treatment. Provision of prophylaxis with trimethoprim-sulfamethoxazole and daily antiretrovirals resulted in a lower rate of 5.4 deaths per 100 person years among the 429 patients assigned to the 'integrated' group (of whom 350 initiated treatment, divided into early or late groups) compared with 12.1 deaths per 100 person years among the 213 patients in the sequential treatment group-a relative reduction of $56 \%(p=0.003)$.

This study demonstrates that initiation of antiretroviral therapy during TB treatment in this patient group reduces the risk of death. Current guidelines recommend antiretroviral therapy to be given in those patients with CD4 counts $<200$. This study adds some support to including those with higher CD4 counts in this advice, particularly as adverse events were reportedly similar in both groups, aside from immune reconstitution events of which none resulted in deaths in the integrated therapy group.

Cain KP, McCarthy KD, Heilig CM, et al. An algorithm for tuberculosis screening and diagnosis in people with HIV N Engl J Med 2010;362:707-16.

Abdool Karim S, Naidoo K, Grobler A, et al. Timing of initiation of antiretroviral drugs during tuberculosis therapy. N Engl J Med 2010;362:697-706.

\section{R Weston}

Correspondence to R Weston, Leeds General Infirmary, UK; rachel.weston@doctors.org.uk

Thorax 2010;65:936. doi:10.1136/thx.2010.145508 